\title{
The architecture of subterranean ant nests: beauty and mystery underfoot
}

\author{
Walter R. Tschinkel ${ }^{1}$
}

Published online: 17 July 2015

(C) Springer Science+Business Media New York 2015

\begin{abstract}
Over the 100 million years of their evolution, ants have constructed or occupied nests in a wide range of materials and situations. A large number of ant species excavate nests in the soil, and these subterranean nests have evolved into a wide range of sizes and architectures. On the basis of casts made of such nests, this variation and the patterns that govern it are described. The possible functions of architectural features are discussed, as are the behavioral "rules" through which the nests are created by worker ants.
\end{abstract}

Keywords Formicidae - Excavation - Soil nesting - Thermoregulation - Division of labor · Vertical organization - Pogonmyrmex badius · Dorymyrmex bossutus . Dorymyrmex bureni $\cdot$ Prenolepis imparis $\cdot$ Solenopsis invicta $\cdot$ Atta $\cdot$ Cyphomyrmex rimosus · Trachymyrmex septentrionalis · Monomorium viridum · Dolichoderus mariae · Formica pallidefulva · Formica archboldi · Formica dolosa · Camponotus socius · Camponotus floridanus · Pogonomyrmex californicus · Odontomachus brunneus · Aphaenogaster floridanus · Veromessor pergandei · Nylanderia arenivaga $\cdot$ Pheidole morrisi

\section{Introduction}

Soil is the medium under our feet, the stuff that we grow our crops in, the foundations for our houses and the basis of all terrestrial ecosystems with their thousands of species. To those animals adapted to live in it, soil is a welcoming medium. It can offer protection from enemies, coddling temperatures, soothing humidity, a refuge

\footnotetext{
$\bowtie \quad$ Walter R. Tschinkel

tschinkel@bio.fsu.edu

1 Department of Biological Science, Florida State University, Tallahassee, FL 32306-4370, USA
} 
from the lethal sunshine and withering heat during the summer, or from paralytic cold during the winter. Even when not a drop of liquid water is to be found above ground, the soil can offer drinkable films of life-giving water to animals small enough to exploit it. But most of us rarely give a thought to the many animals that create burrows, homes, galleries, cavities and tunnels in the soil. Among the most common soil-dwelling animals in most of the warm areas of the world are the ants, many of which are consummate diggers. All 20,000 species of ants are social, living in colonies that function like organisms, in the sense that it is the colony that reproduces, the colony members merely being the gears and levers of this self-reproducing machine. Ants, like social wasps and bees, are all-female societies in which the colony is a family and consists of more-or-less sterile workers along with a single individual (or a few) that lays eggs (the queen). This sharp division of labor is further subdivided among the workers on the basis of age. Young workers function as nurses caring for their larval sisters. As they age, they take on more general nest maintenance, transport and processing, and only toward the ends of their lives do they leave the nest to forage, bringing food back to be shared among their sisters, and meeting an early death as a consequence.

The nesting habits of ants are quite varied, ranging from excavated soil nests, to rotten wood, to cavities in living trees, or even nests constructed of carton. In this essay, we will focus only on nests excavated in the soil, for excavation and construction are fundamentally different behaviors. In the context of biomimicry, the implication is that there is engineering wisdom to be gained from the ants, but it is important to understand that ant nests are evolved not designed. They are not engineered entities such as human houses, bridges and other structures. Ant nests, like the ants themselves, evolved over millions of years through the addition of small changes to whatever existed at the time. Gradually, species of ants diverged from one another through these incremental changes, gradually producing the modern fauna of about 20,000 species, and at the same time, through the same gradual modification of behavior, producing the range of nest architectures we see today. A more complete literature review of ant nest architecture can be found in Tschinkel (2011).

\section{The ancestral nest}

What did the ancestral ant nest look like, and how was it modified through evolution? The ancestor of all ants was probably a solitary wasp whose females excavated a nest in the ground in which she raised her offspring (Wilson 1971). Sociality evolved when the female and her offspring shared the nest for much of their lives, gradually dividing up the duties of reproduction and work to produce the first ant societies from which all modern ants descended. Although we do not have fossils of these ancestral ant nests, we can guess that they probably looked like the nests of many ground-nesting wasps and bees-simple vertical or angled burrows with an enlarged chamber at its lower end, or perhaps several small chambers off the main burrow. Just as the evolution of ants began with a single individual, the life cycle of many ants begins by recapitulating what is essentially the ancestral condition-a single mated queen, soon to be mother of a family. This queen digs what is essentially a facsimile of the ancestral nest, a 


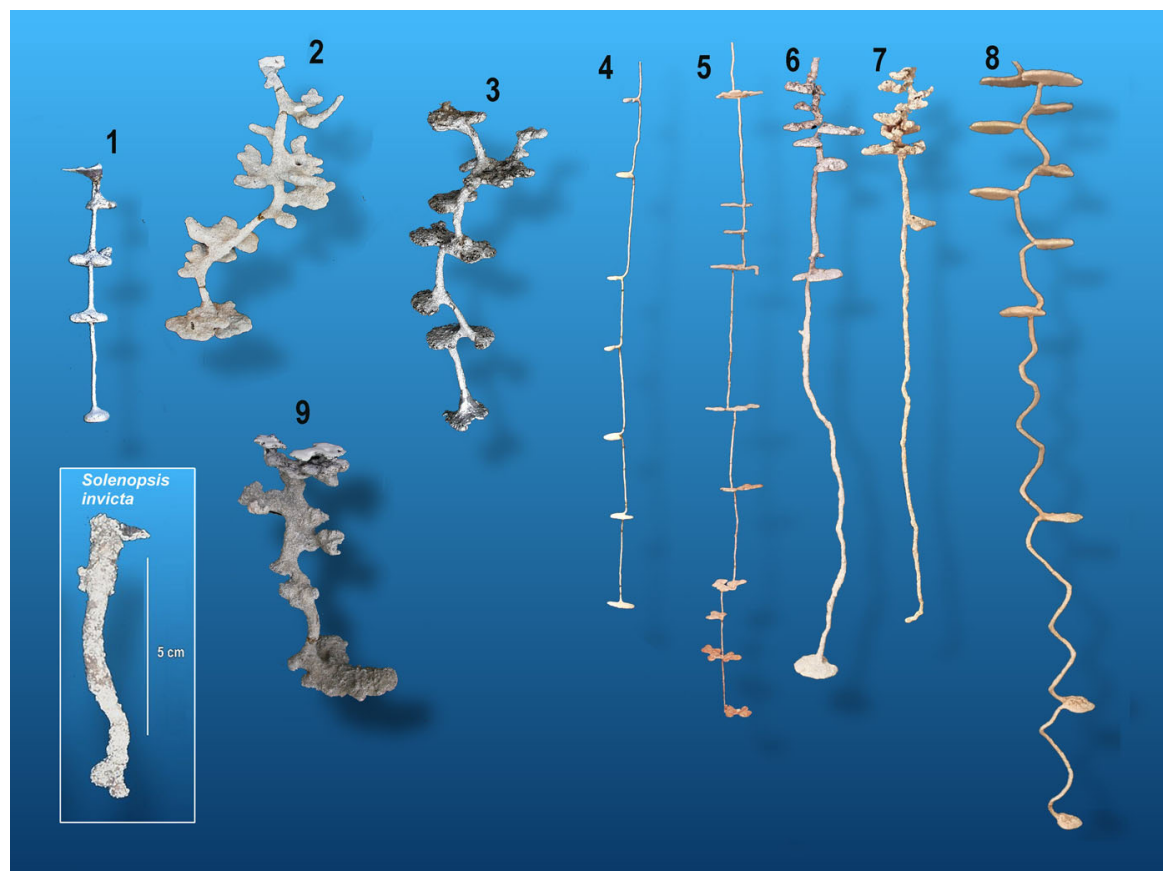

Fig. 1 The majority of subterranean ants nests are composed of variations of the same basic unit, a moreor-less vertical shaft connecting more-or-less horizontal chambers. Some of the examples shown are not complete nests, e.g. numbers 4, 5 and 8 . The nests are not shown to the same scale. Inset .It seems likely that all modern ant nests evolved from a simple burrow with one or a few chambers. Many modern ant species recapitulate this simple stage during the founding period when the newly-mated queen constructs such a simple burrow-with-chamber. The example shown is of the fire ant, Solenopsis invicta

simple burrow with a chamber at its end (Fig. 1, inset). After the queen has produced the first brood of workers from reserves stored in her body, these workers enlarge the nest by adding chambers, enlarging chambers and deepening the nest as the colony grows. In a general sense, the nest grows much as it evolved. Moreover, its basic unit of structure remains the same in almost all ground-nesting ants-a more or less vertical shaft connecting more or less horizontal chambers (like shish-kebobs, Fig. 1). In the course of evolution, all elements of this basic unit have been modified to produce the range of nest architectures we observe today. ${ }^{1}$

\footnotetext{
1 Methods for studying nest architecture (Tschinkel 2010): The architecture of subterranean ants nests can be rendered by careful excavation, layer by layer, exposing each chamber in turn. This can reveal the chamber outlines, chamber depth and orientation, but it does not record connecting shafts very well, nor does it record characters such as chamber ceiling height, fine structural details and so on. In contrast, filling the hollow space of an ant nest with a casting material can produce a three-dimensional cast that is faithful in even tiny details. The casting material used will depend on the purpose of making the cast. When the nest contents are to be retrieved, the best material might be paraffin wax (or possibly dental plaster). The wax can be melted or the plaster dissolved to retrieve the ants. When the purpose is simply to render the space visible for a display (e.g. a museum), the best material will be a molten metal, with the ideal being aluminum because of its strength. However, zinc is better for nests with smaller diameter shafts and finer structure. The higher melting point of aluminum means that it cannot cast very fine structures.
} 
Thus, for most of the life cycle, it is the colony that creates the underground nest. It is one thing to imagine a single animal digging a nest of some specified shape. After all, we can all think of examples. But it is entirely another when the characteristic nest architecture is created by a group of individuals, for they must all respond to each other and to the growing nest in particular ways to produce the consistent outcome we see. This fact is the charming, central mystery of social insect behavior, for everything they accomplish they accomplish without a leader, without a blueprint, without a plan, without prior instruction, and in the case of subterranean ant nests, in the dark, but with a shared set of behavioral rules. In brief, the workers' behaviors that create the nest are self-organized (Rasse and Deneubourg 2001; Buhl et al. 2006). Each worker carries within herself the "instructions" of what to do given a certain context, how to interact with other workers and the forming nest, and when to do it. The tasks are carried out in "series-parallel", that is, each worker does a small part of the job, whereupon another worker may do the next step, while the first responds to something else. Because labor is highly redundant, the work gets done in thousands of little steps, each seeming perhaps undirected, random or even backwards, but statistically, progress is directional, and the nest gradually appears. There is a broad division of labor that makes some workers more likely to initiate a new nest site, others to dig, to carry sand, to transport brood to the new nest and still others of yet unknown function, yet within these broad categories, workers are interchangeable (Beshers and Fewell 2001). In essence, the colony as a whole behaves like an organism (Camazine and Deneubourg 2003; Hölldobler and Wilson 2009). Organisms are entities composed of cells whose cooperation is so well-honed that we fail to recognize them for what they are-the ultimate, perfected self-organized, self-reproducing machines. Perhaps we are blinded to this truth by the fact that the cells all stick to one another, whereas the members of an ant colony are free to roam about. Yet, to see the colony as a "superorganism" parallel to organisms is to perceive its most fundamental character-an entity whose members all pursue the common goal of self-reproduction. Neither the cells of an organism, nor the workers in a colony have a reproductive future save through the entity of which they are a part.

Our understanding of how self-organization works is dim, but because the nests of ant species occur in a wide range of shapes and sizes, it is clear that subtle evolved changes in worker behaviors and sensory responses produce shifts in self-organization that in turn produce nests that are quite different. This thought should be kept in mind as I describe the variety of architectures across ant species.

\section{Evolution and range of architectural variation}

With this background, we can see that most ant nests have been derived from the (presumed) ancestral nest through the addition of chambers, changes in chamber shape and spacing, maximum depth and total chamber area (or volume). These elements seem to have been modified with a large degree of independence from each other, suggesting a degree of independence of the self-organizing programs. Chamber spacing may be increased or decreased independently of other architectural features (Fig. 2). Chamber outline may be modified with little change in other elements, although there 
Fig. 2 Most elements of the nest architecture seem to be able to evolve more-or-less independently of one another. In this example, the most obvious difference between the nests of Monomorium viridum (left) and Dorymyrmex bossutus (right) is the spacing between the chambers. The shafts connecting chamber in $M$. viridum are extremely short, while those in D. bossutus are long

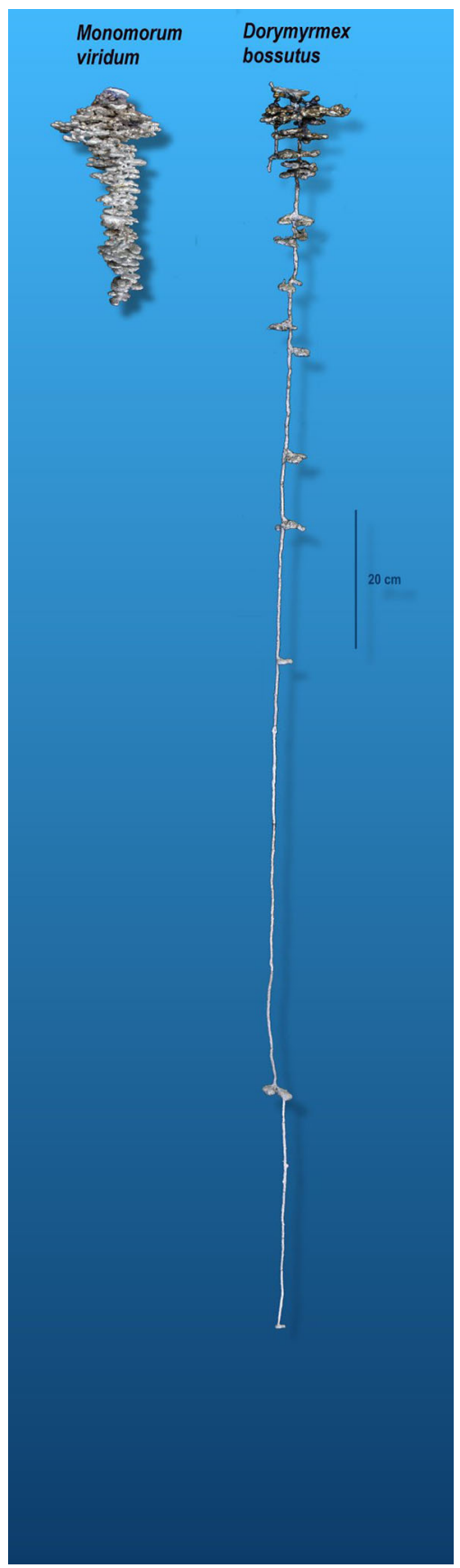

is a strong trend for the chamber outlines to become lobed as the ants enlarge them (Fig. 3a, b). Maximum nest depth may change with little change in other elements (Fig. 4). 

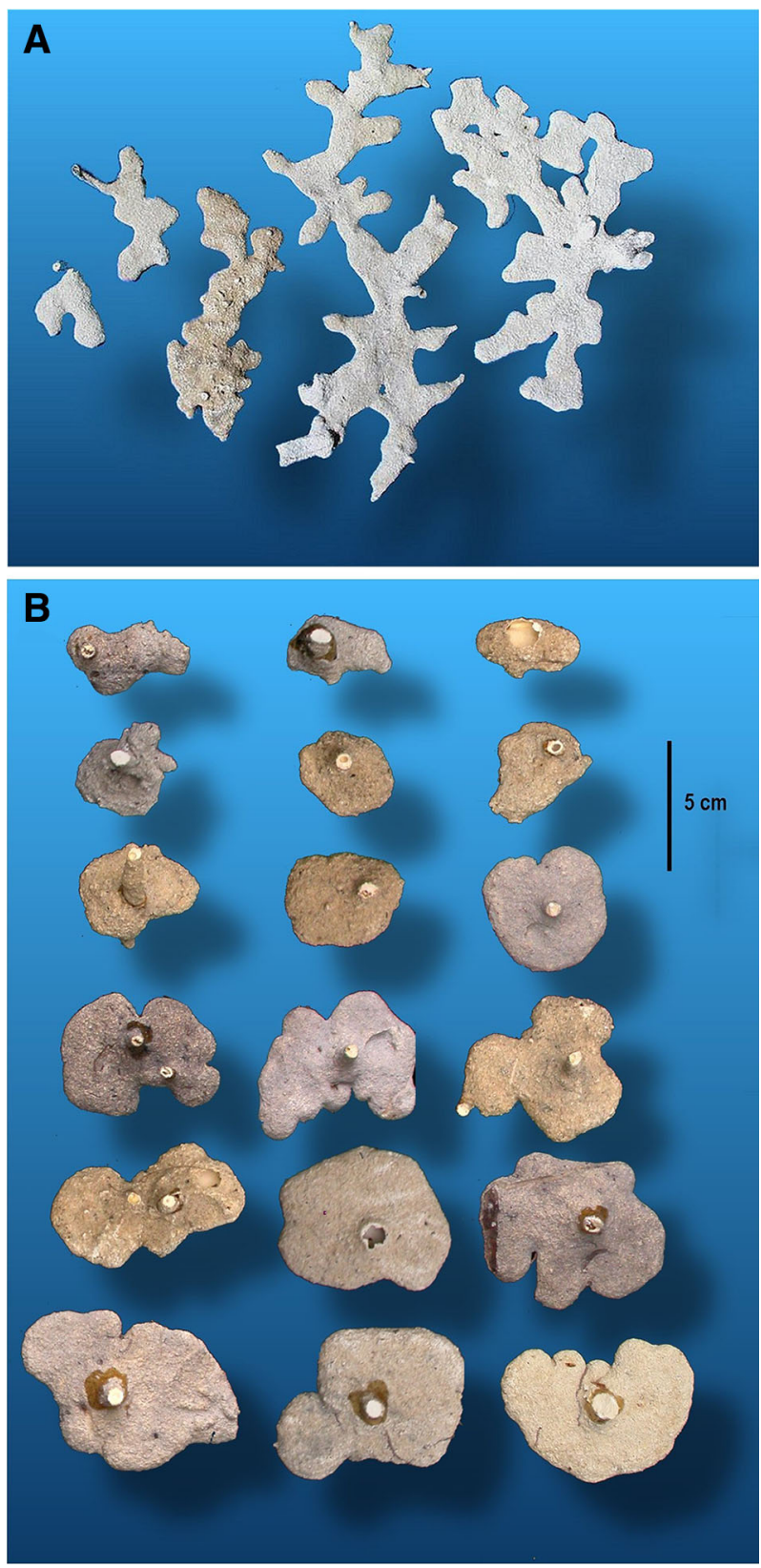

Fig. 3 Chamber outlines often become more lobed as the chambers are enlarged, but this is not universal. In Prenolepis imparis (a), lobes arise even when the chambers are incipient, but in Aphaenogaster floridanus (b) even the largest chambers are only moderately lobed 


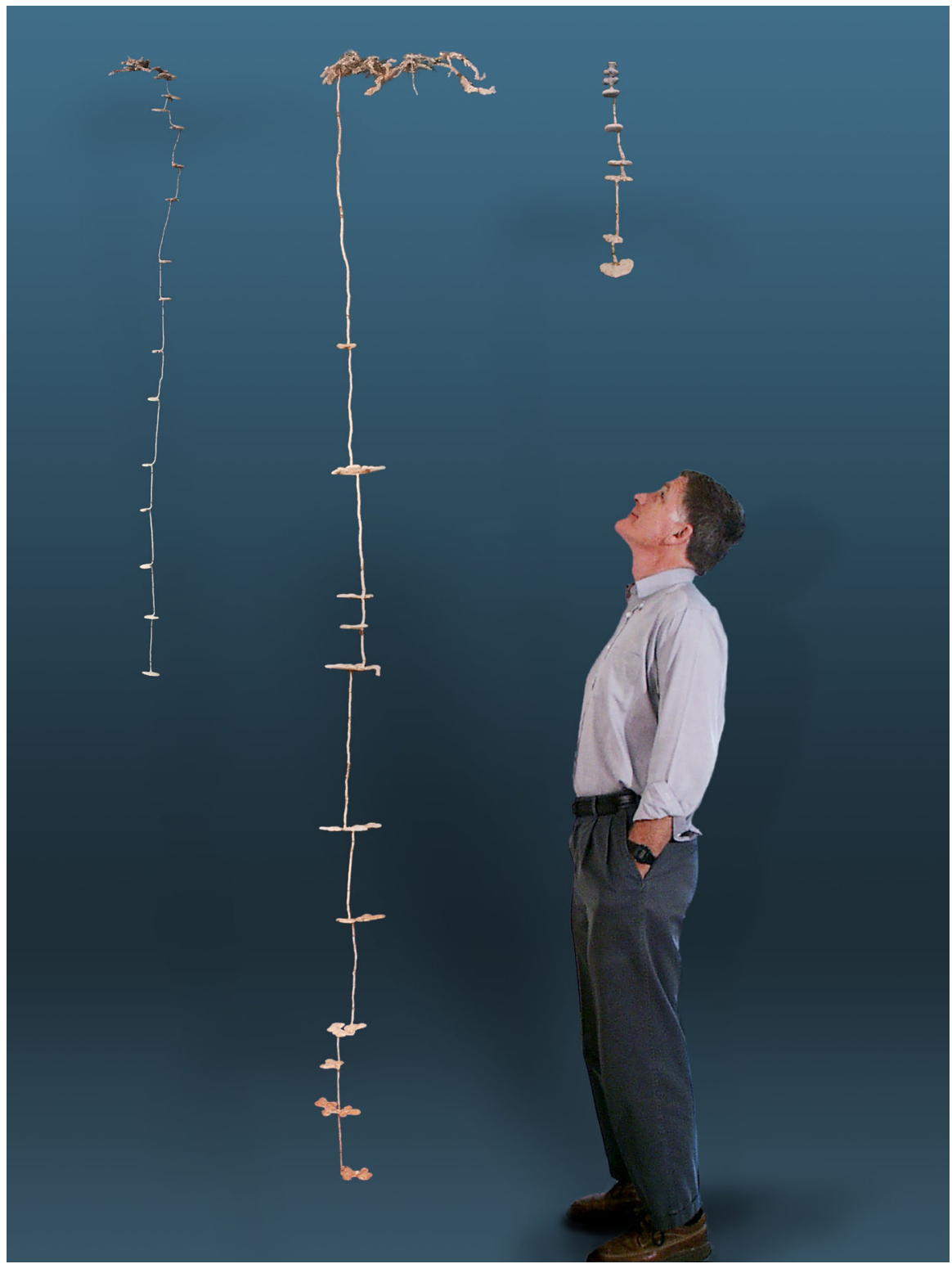

Fig. 4 Maximum nest depth varies greatly among species, even when other elements are rather similar. Dorymyrmex bureni (left), Prenolepis imparis (center, Tschinkel 2003) and Aphaenogaster floridanus (right)

Although most of the connecting shafts are more or less vertical, in some species they are distinctly to greatly angled (Fig. 5). Pogonomyrmex badius is a special case of angled shafts, for the shaft is wrapped into a helix (Fig. 6a), a condition that is particularly apparent at depth (Tschinkel 2004). This condition is also apparent in Pogonomyrmex californicus, although the helix is much looser (Fig. 6b) (unpublished data). 

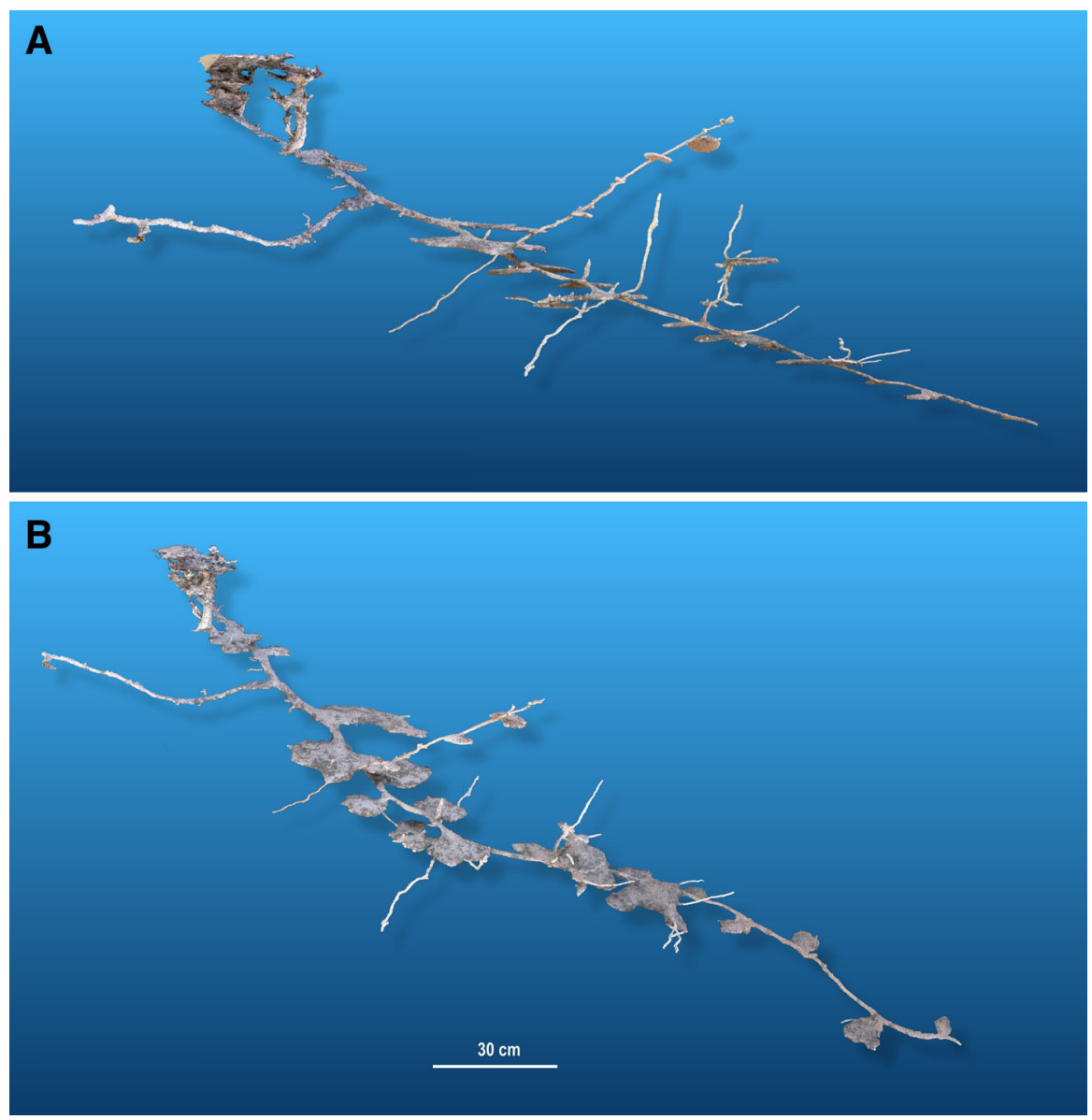

Fig. 5 In some species, the shaft is not vertical, but distinctly angled. This is expressed to an extreme degree in the desert dwelling Veromessor pergandei shown here. a A view directly from the side and $\mathbf{b}$ a $3 / 4$ view showing the chambers

In many species, the chambers just below the soil surface are qualitatively different from those at greater depth. In P. badius (Fig. 7a), these near-surface excavations result from the enlargement and branching of horizontal, linear tunnels, eventually creating very large chambers of complex outlines. The deeper chambers begin as rounded circular or oval outlines and become lobed as they are enlarged. It is thus likely that near-surface chambers and deeper chambers result from different behavioral programs (Tschinkel 2004). Other examples of such architectural differences in nearsurface and deep chambers include Prenolepis imparis (Fig. 3) (Tschinkel 1987), $P$. californicus (Fig. 6b), F. pallidefulva (Mikheyev and Tschinkel 2004), Dorymyrmex bureni (Tschinkel 2003) and D. sp. (Fig. 7b, c) (unpublished data).

Variation of architecture within a genus is particularly interesting because it reveals the relatively recent modifications of behaviors and nest elements leading to distinct architectures among related species. In three species of north Florida Formica, the 

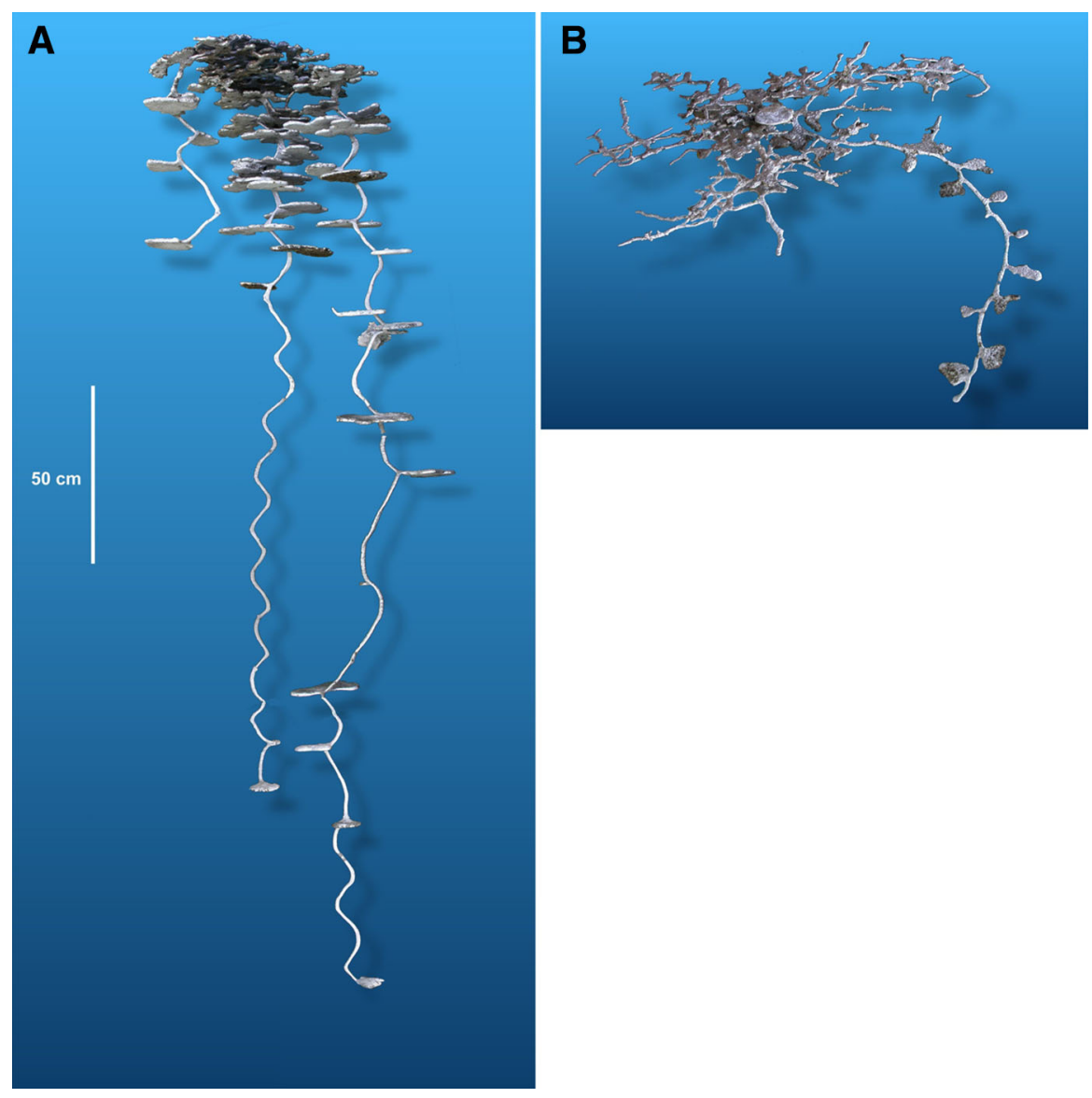

Fig. 6 In Pogonomyrmex badius, the shaft is also angled rather than vertical, but it is wrapped around an imaginary cylinder to form a helix (a). In (b) P. californicus, the helix is much looser (the cast is incomplete)

architecture is distinguished primarily through single versus multiple shafts, angled versus vertical shafts and concentration of chamber area near the surface versus near the bottom of the nest (Fig. 8) (unpublished data). F. archboldi and F. pallidefulva most commonly have single shafts with a greater concentration of chamber area near the surface, but the shaft is usually vertical in $F$. archboldi while it is angled in $F$. pallidefulva. The nests of $F$. dolosa consist of multiple, mostly angled shafts with chamber area concentrated near the bottom of the nest. The nature of the individual chambers remains similar in all three species-relatively small in comparison to the ants' body size, simple and rather "clunky." Similar within-genus comparisons can be made for three north Florida Aphaenogaster species (Tschinkel 2011).

Although most chambers are flattened in vertical aspect, in some of the fungus gardening ants, the chamber shape has been converted from the widespread pancake shape to egg shaped (Fig. 9) (Tschinkel 2003; Moreira et al. 2004a, b; Solomon et al. 

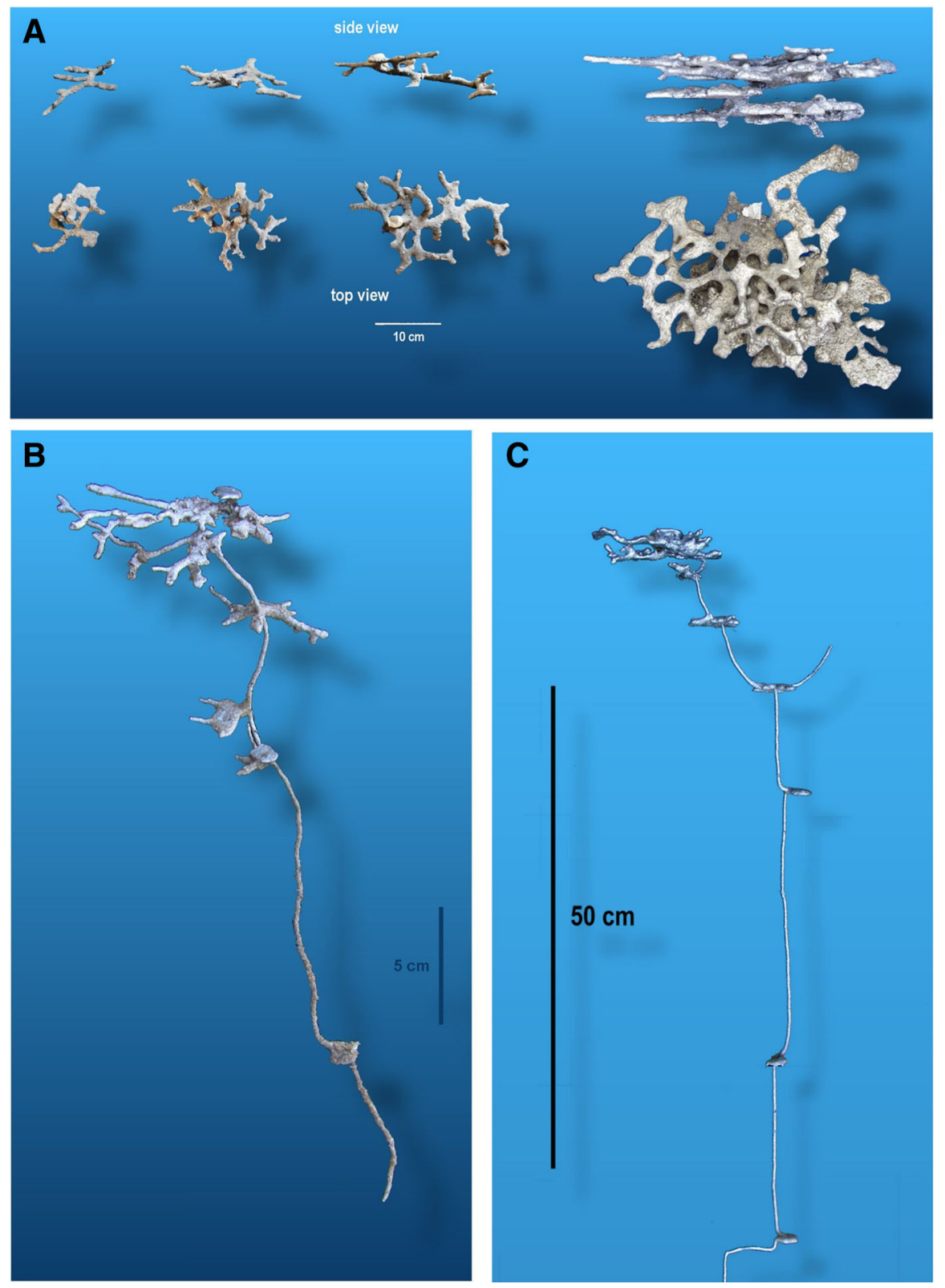

Fig. 7 Near-surface chambers in some species are qualitatively different than deeper chambers in that they are more like branching horizontal tunnels rather than enlarged ovals. a P. badius (Tschinkel 2004), b Dorymyrmex sp. and c Dorymyrmex bureni

2004; Rabeling et al. 2007), showing that even this element is mutable. The egg-shaped chambers accommodate the fungus gardens (Fig. 9, inset). Some species seem to have abandoned highly regular architecture entirely, as for example the fungus gardener, 


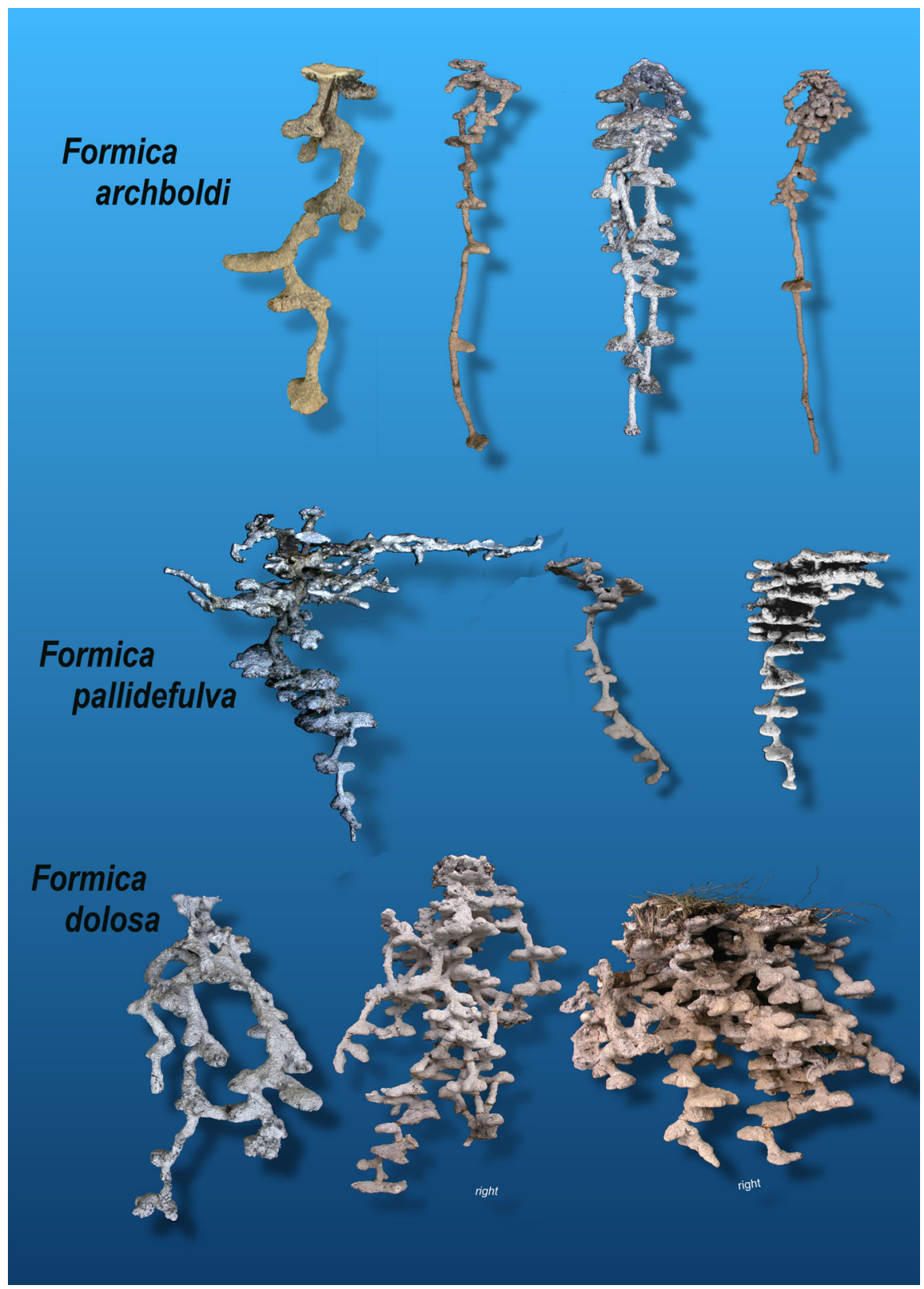

Fig. 8 Within the genus Formica, the elements that differ among these three species are the number and angling of the shafts, and the concentration of chamber area near the top or bottom of the nest

Cyphomyrmex rimosus and the Florida carpenter ant, Camponotus floridanus (Fig. 10) (unpublished data). Even the Argentine ant, Linepithema humile has tendencies in this direction (unpublished data). Species of Nylanderia seem to forgo excavating 


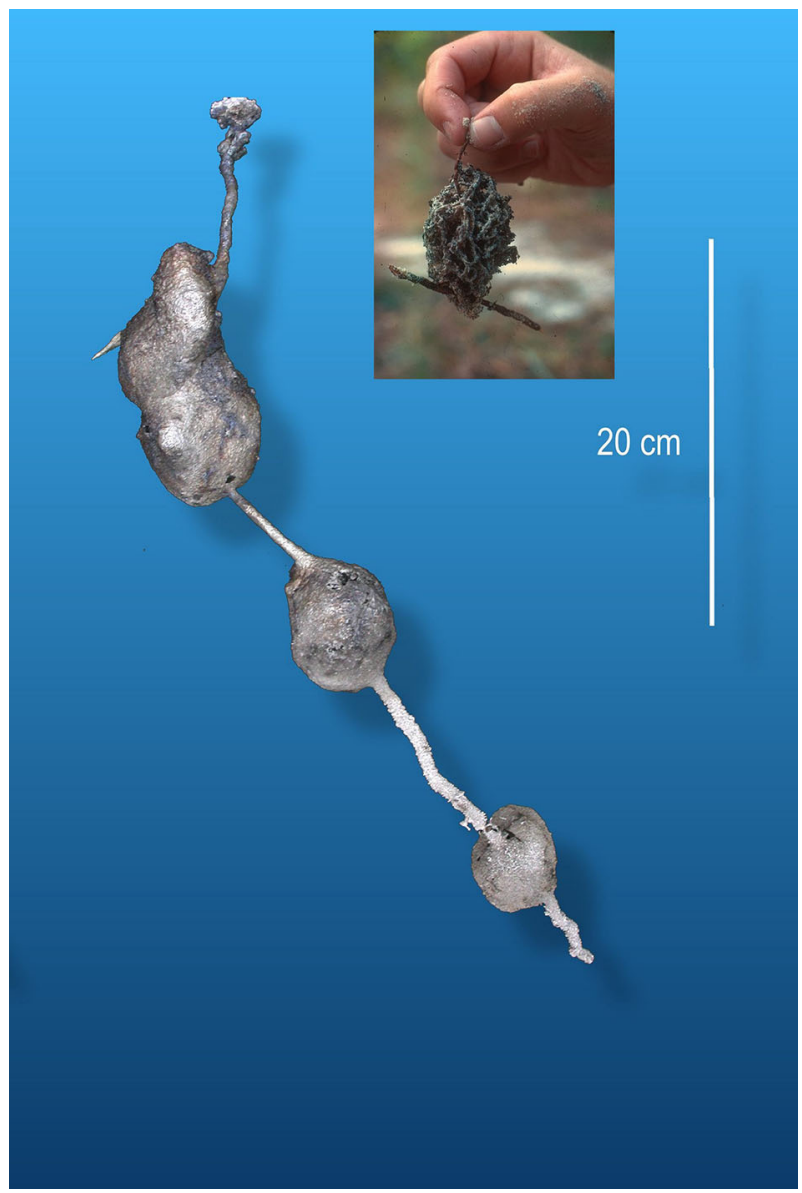

Fig. 9 In the fungus gardening Trachymyrmex septentrionalis, the chambers are egg-shaped rather than flattened in order to accommodate the fungus gardens (inset)

distinct chambers, creating only lateral bulges in their vertical shafts (Fig. 11). On the other hand, they consistently construct a second vertical shaft that does not connect directly to the surface, but rather to the primarily vertical shaft (unpublished data). Dolichoderus mariae appears to have abandoned all pretenses of aesthetics and simply excavates the soil under grass clumps to form a large, irregular cavity exposing the grass roots that the colony then uses as a scaffold on which to hang itself and its brood (Fig. 12) (Laskis and Tschinkel 2009).

\section{Nest growth}

During the life cycle and colony growth, all elements of the nest are enlarged so that the proportions of the elements to each other remain more or less constant (Fig. 13) (Tschinkel 2005, 2011). It is the conservation of these proportions, no matter what 


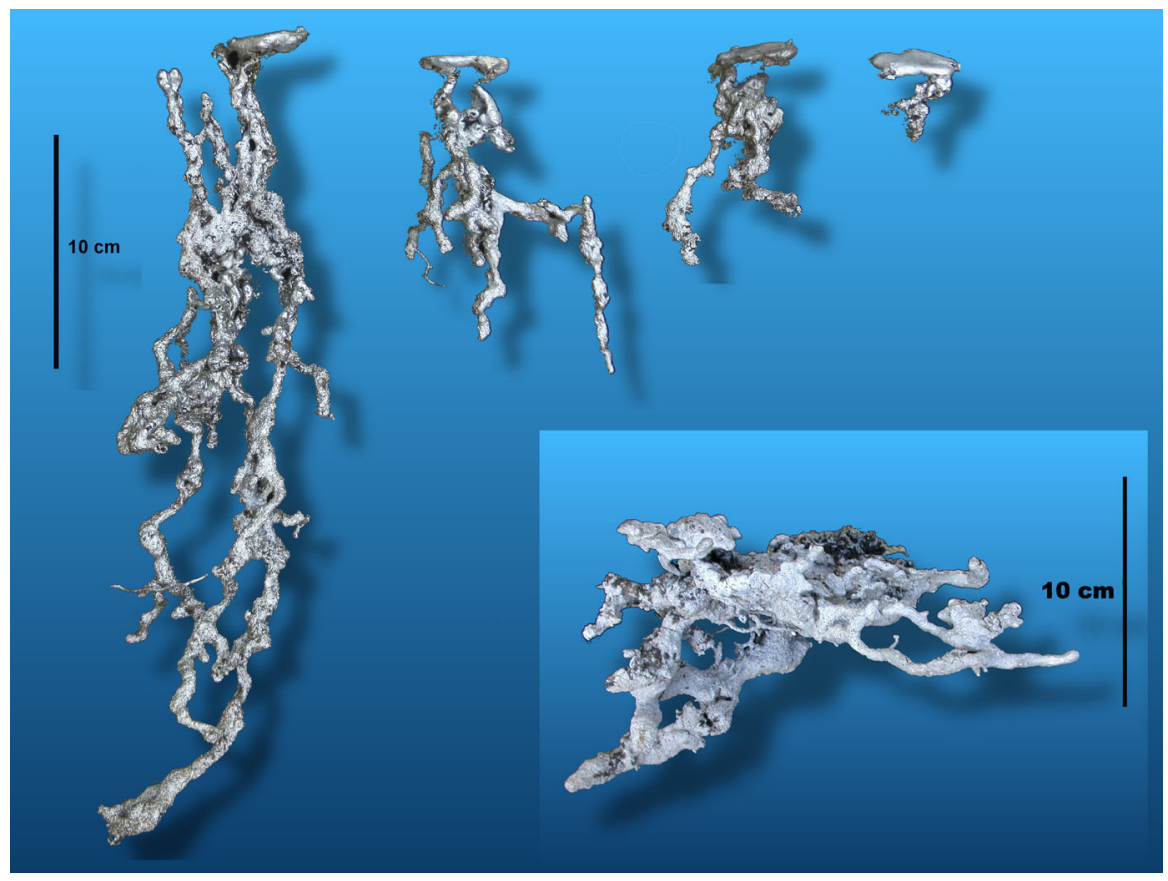

Fig. 10 In some species, such as the fungus gardener Cyphomyrmex rimosus, the architecture lacks regularity and appears to consist of rather haphazard shafts without distinct chambers. This is also seen in Camponotus floridanus (inset)

the size or stage of development, that creates the species-typical nest architecture. In addition to such growth of the basic nest unit, some species enlarge the nest by adding shish-kebab units to make nests composed of multiple units. Spacing between units can be considerable, as in P. badius (Fig. 14a) (Tschinkel 2004), minimal as in Ph. morrisi (Fig. 14b) (unpublished data) and touching as in the fire ant, Solenopsis invicta (Fig. 14c) (Cassill et al. 2002). An interesting consequence for the first two is that in order to move between the vertical units, ants must travel to the near-surface before descending into another unit. What consequences this might have for colony organization and function is unknown.

In all species, the nest is enlarged as the colony grows, but the total chamber area and depth may grow faster, slower or at the same rate as the number of workers. When the growth rate of the two is different, the ants may become, on average, more crowded or less crowded, with unknown consequences for social interaction. However, the meaning of this overall density is not clear because in most species, the ants are generally more crowded deep in the nest, and also move up and down within the nest to track environmental conditions (Penick and Tschinkel 2008).

It should be no surprise that the total size of subterranean ant nests is generally related to both the size of the colony that built it and the size of the ants that live within it. This suggests that there is feedback from the nest size to the worker behavior such that nest enlargement reaches a limit set by the colony size. Such feedbacks can apply 
Fig. 11 Nylanderia arenivaga nests lack distinct chambers but always have the second shaft connecting to the main shaft by a lateral tunnel. This cast is incomplete

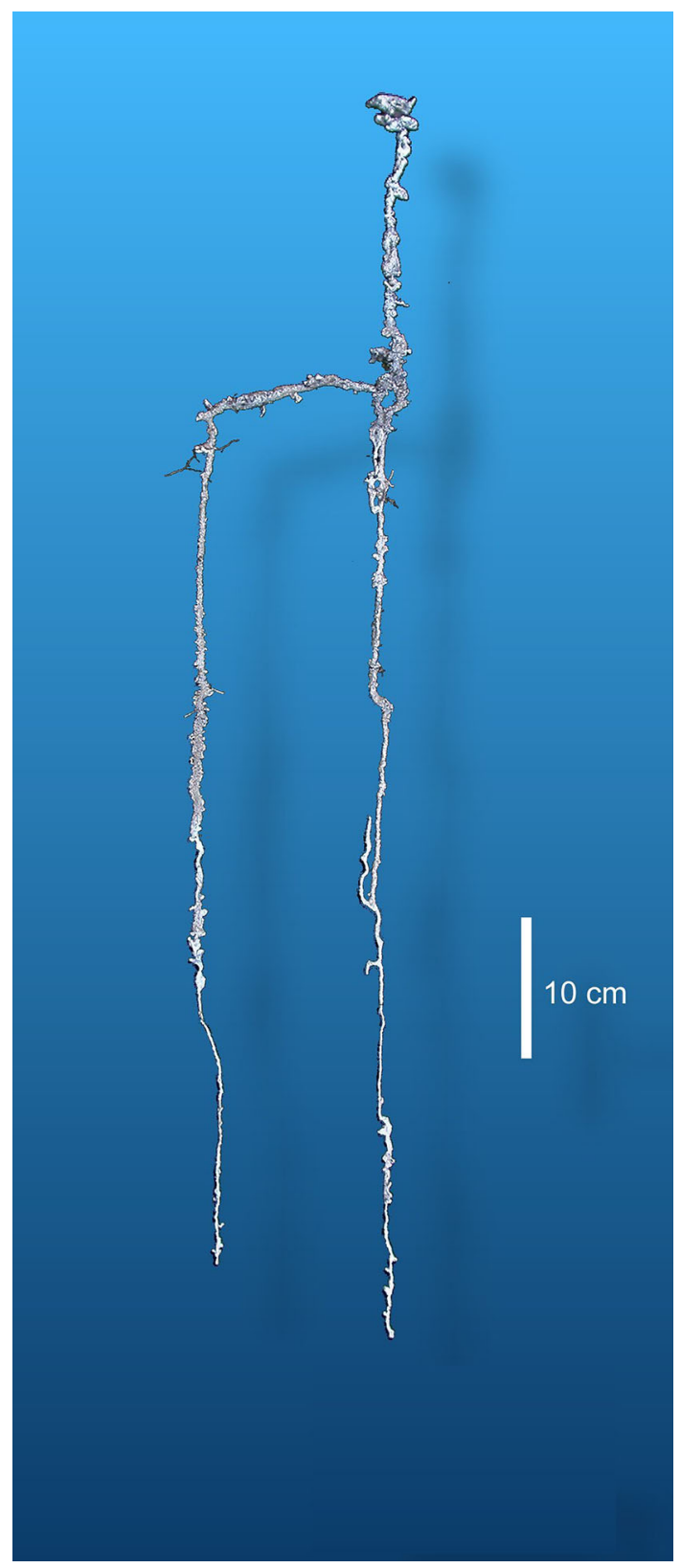

not only to the whole nest, but also to different levels, assuring that certain architectural proportions are preserved. Ant nests range from thimble sized to the truly monumental excavations of the higher fungus gardening ants in the genus Atta (Jonkman 1980a, b; Moreira et al. 2004a, b). Figure 15 shows nests built by approximately 6000 Monomorium viridum, a very small ant, 6000 Pheidole morrisi, a medium-sized ant, and $P$. 

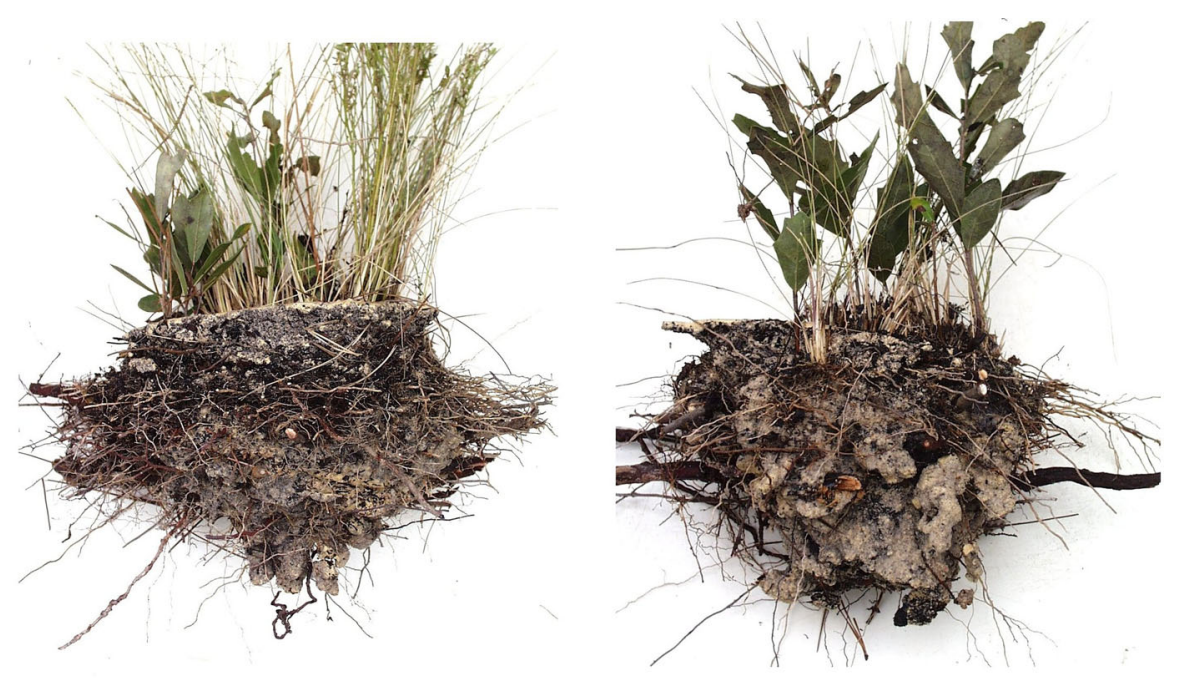

Fig. 12 The polygyne, polydomous ant Dolichoderus mariae simply excavates the soil beneath grass clumps and uses the exposed roots as a scaffolding on which to hang the workers and brood (Laskis and Tschinkel 2009)

badius, a large ant. Larger ants need larger diameter shafts and higher chamber ceilings than do smaller ones. Moreover, at the same level of crowding, larger ants will dig larger chambers than smaller ants. Whether there are general rules that apply across ant body sizes is yet unknown, but there ought to be a fairly tight relationship between shaft diameter, chamber area, ceiling height and the body size of the ants. From an energetic investment point of view, there should be an optimum relationship among these variables. Smaller dimensions would create crowding that could interfere with efficient movement and work, whereas larger values would expend unnecessary energy in soil removal and transport.

\section{Function and organization of work}

Because ant nests have evolved to be species-typical, it is reasonable to assume that the architecture is functional. Of course the most basic functions of shelter, defense and microclimate are obvious and need hardly be pointed out. What is meant here is that, in some as yet unclear way, the particular features of architecture enhance the colony's fitness by acting on some aspect of production or efficiency. Perhaps a particular distribution of vertical chamber area, chamber shape or spacing between chambers, or total area or maximum depth, maximizes fitness by allowing the production of more sexual alates, or their production at lower cost. Brian (1956) showed that work-group efficiency declined as group size increased, suggesting a possible function for chamber size. Experiments with the fire ant, Solenopsis invicta, supported the hypothesis that chamber size may be important to colony efficiency. In laboratory experiments, the efficiency with which workers reared brood (i.e. new workers per old worker per month) decreased as the size of the worker group increased (Michener 1964; Porter 


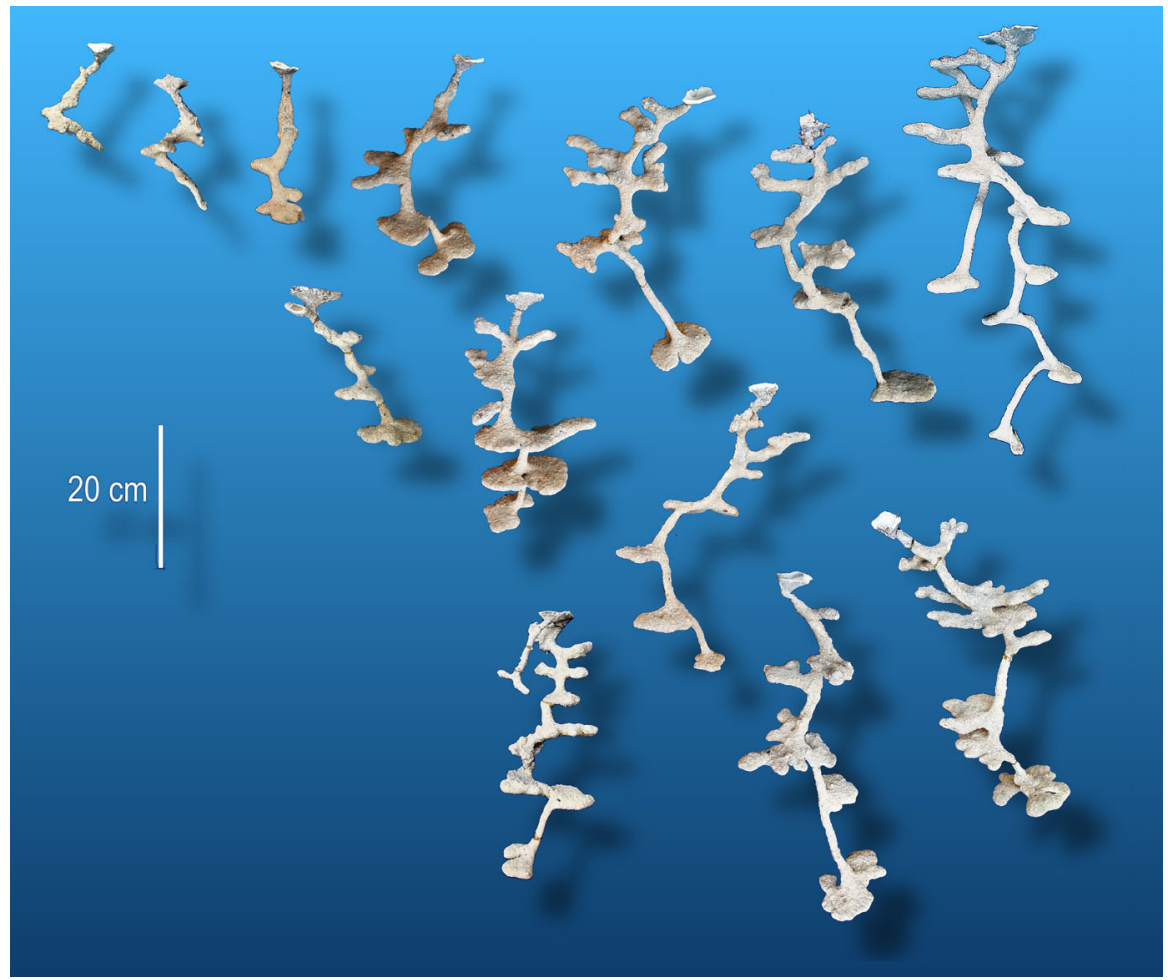

Fig. 13 During colony growth and nest enlargement, all elements of the nest architecture are simultaneously enlarged, thus preserving the proportions and giving the nest its species-typical appearance. The example shown here is Camponotus socius (Tschinkel 2005)

and Tschinkel 1985; Karzai and Wenzel 1998). However, in natural colonies of the fire ant, larger colonies reared brood just as efficiently as did smaller ones (Tschinkel 1993). Natural nests are composed of dozens to hundreds of chambers averaging about $5 \mathrm{~cm}^{2}$, limiting the size of the work group to about 200 ants (Cassill et al. 2002), far smaller than the laboratory experiments. This suggests that one effect of the subdivision of the natural nests into many chambers is to limit the size of the work groups and thus to maintain a high brood-rearing efficiency. Whether this is true of other ant species is not known.

Another example of function is suggested by the upward movement of aging workers in harvester ant nests (and many other ant species) (MacKay 1983; Tschinkel 1999; Hart and Tschinkel 2012; Kwapich and Tschinkel 2013). Brood are found primarily in the bottom third or so of the nest, seeds in a zone above that but still well below the surface, and foragers only in the top 10-15 cm. Young workers engage in brood care and are found mostly in the bottom third of the nest, middle aged workers take on several maintenance, transport and processing duties in the middle regions and only older workers act as defenders and foragers at the top. The upward movement combines with the vertical nest structure to separate each set of duties into different zones of the nest in an assembly line fashion. This linear separation probably increases the 

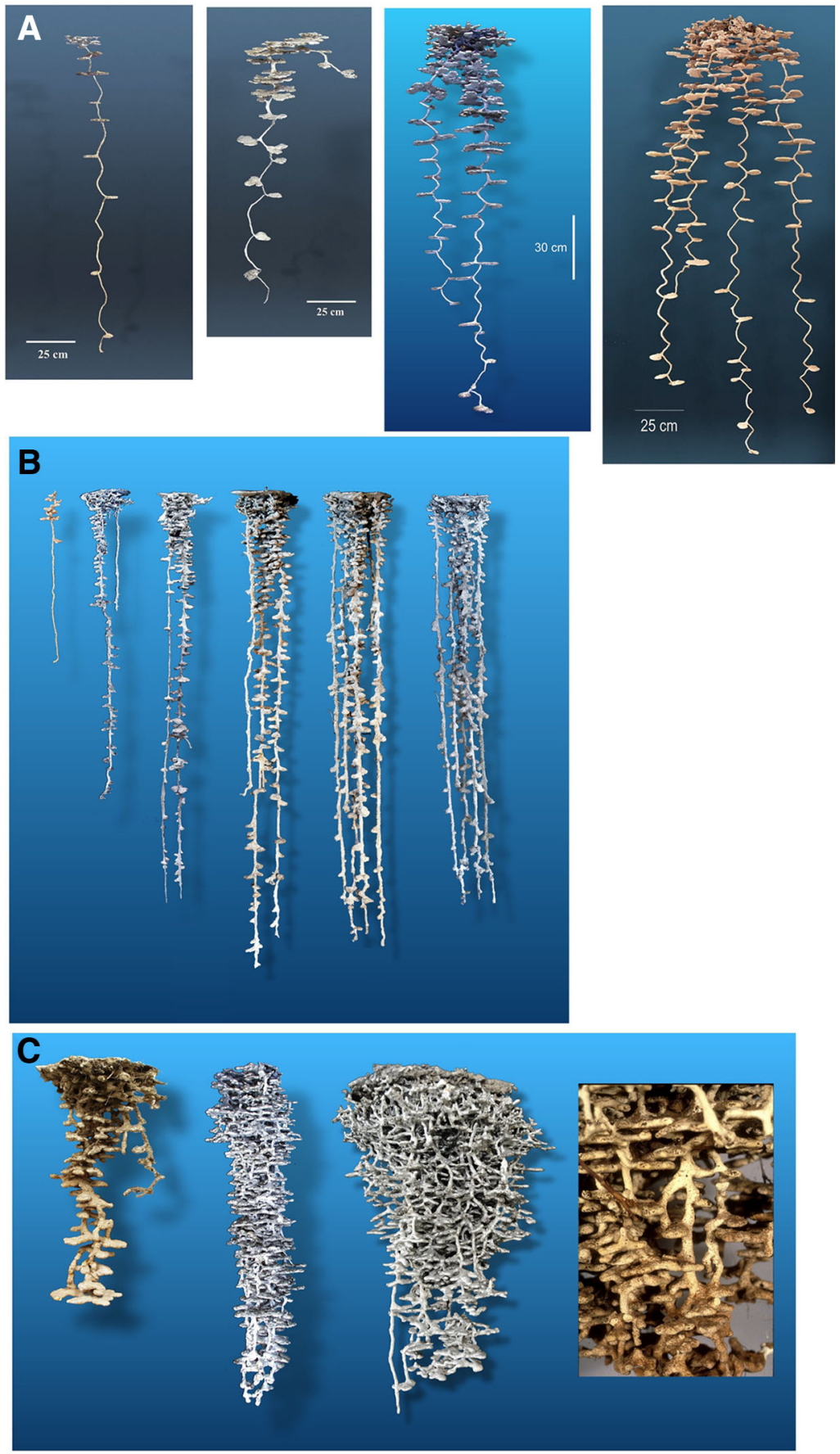

Fig. 14 Three examples of nest enlargement among species with multiple-shaft nests. The nest is enlarged during colony growth in part by adding more shish-kebab units, but also by adding more chambers, deepening the nest and enlarging chambers. a P badius (Tschinkel 2004), b Ph. morrisi and $\mathbf{c} S$. invicta 


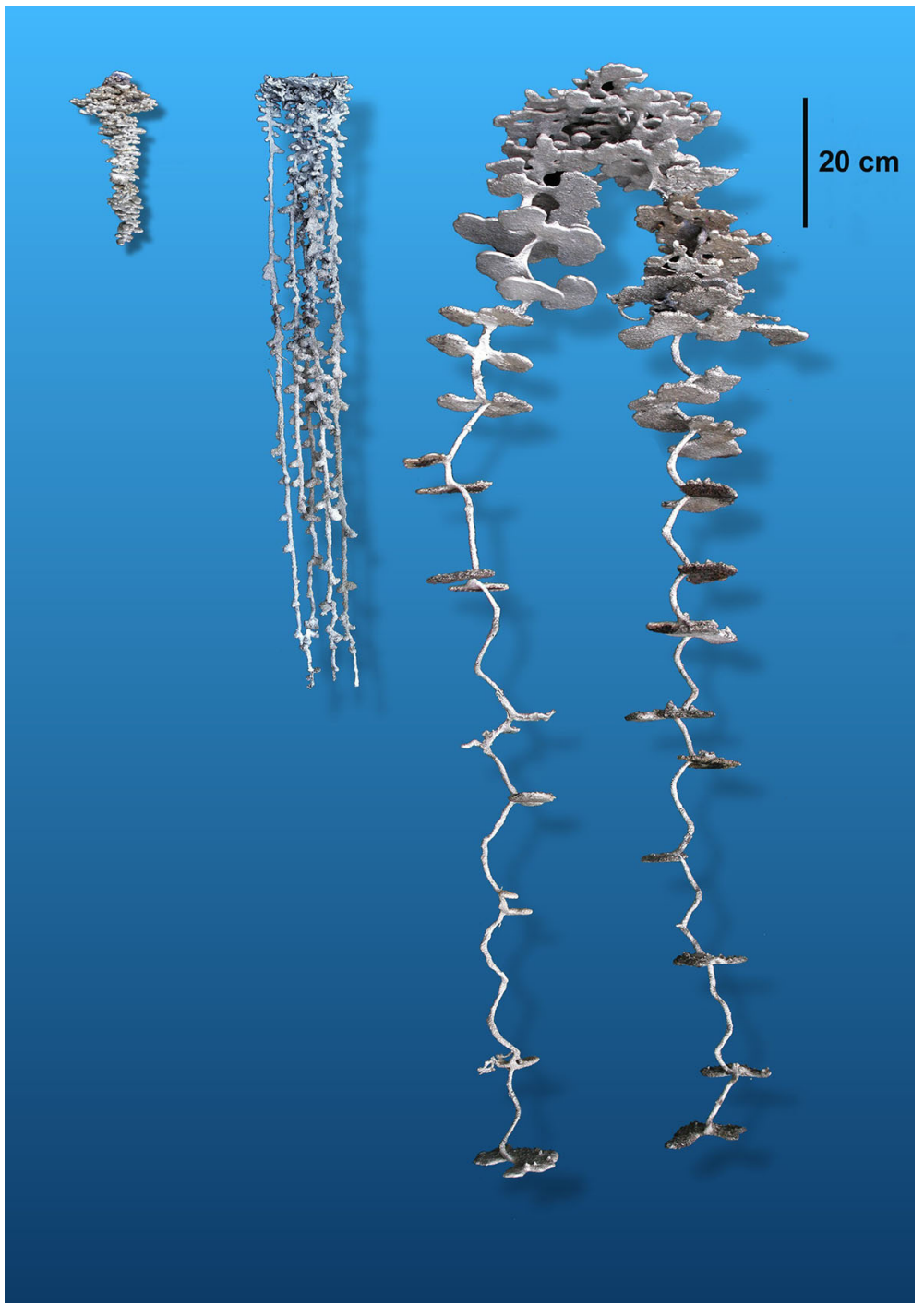

Fig. 15 Nests vary enormously in total volume according to species and body size of the ants. All of three of these nests housed approximately 5000-6000 ants. The nest of the tiny ant Monomorium viridum is much smaller than that of the medium sized Pheidole morrisi, which in turn is much smaller than that of the large ant $P$. badius

efficiency of a number of colony functions just as a factory assembly line increases the efficiency of automobile production. Although it may not be possible to attribute this presumed efficiency to any specific architectural feature, the vertical spread of many ant nests suggests similar segregation of work duties. Even ants with simple, single-chamber nests between stones show a centripetal movement of aging workers away from the central brood pile (Sendova Franks and Franks 1995). 
The nest also provides the ants with a range of microclimates and temperatures, a range which most ants seem to exploit by moving themselves and their brood into zones with favorable temperatures and humidities (Penick and Tschinkel 2008). In the fire ant, Solenopsis invicta, construction of the heat-collecting mound has been shown to provide an approximately $10 \%$ brood production benefit (Porter 1990). Many species of ants move brood into and out of near-surface chambers or under stones on a daily cycle to track favorable brood-rearing conditions.

Much more mysterious is why a lobed chamber should provide some benefit over a simple oval one, or why variable spacing between chambers might be beneficial. Other features of mysterious possible benefit include the maximum depth of the nest, and the top-heavy nature of many nests, that is, the disproportionate amount of chamber area near the surface. Of course it is possible that some features have no demonstrable fitness effects, and are simply meaningless epiphenomena of the behavioral mechanisms that created the nest. It is unlikely that every architectural detail is functional, or at least, it would be extremely challenging to test such details.

In order to create the vertically structured nests of many species, the ants must possess information with respect to their current depth below the surface. Such information is also necessary for the vertical arrangement by worker age. Tschinkel (2004) proposed that soil carbon dioxide gradients could provide such information, but his experiments later showed this not to be true (Tschinkel 2013). Nest excavation in harvester ants occurs in part through a chain of transport in which a pellet of soil is removed, moved upward, deposited and picked up by different workers until it is finally deposited on the soil surface (Rink et al. 2013). Most of how ants construct nests is still a mystery, although a few hints do exist. Although termites construct rather than excavate their nests, the same behaviors basic to self-organization can result in pillars, walls, galleries or chambers depending upon pheromonal and air flow conditions (Bonabeua et al. 1998). One can imagine that the basic ant behaviors of digging, pellet formation, pellet transport and deposition could be elicited and modified by varying local conditions to produce nests of a particular architecture.

\section{Does ant nest architecture offer wisdom for humans?}

What might ant nest architecture have to offer humans? No doubt, when rendered visible by casting, the nests present appealing objects of great beauty. Appreciation is enhanced by the knowledge that the ants constructed these nest in the dark, without a leader and without a plan. Few humans live underground, and when they do, as in the loess areas of Tunisia and northern China, the architectural rules of excavation seem largely inspired by "normal" houses whose spaces are simply created underground. The excavated cities of Cappadocia in Turkey seem more ant-like in flavor with much less resemblance to "normal" houses and more to ant nests. Moreover, from a human point of view, the evolved nests of ants have features that engineered human space would strictly avoid. An architect who built a tall building in which inhabitants have to take the elevator all the way to the top in order to access an adjacent series of rooms below would have a short career. On the other hand, designing rooms of sizes appropriate to their purpose is already very much a part of human architecture. Perhaps someday 
an adventurous architect will design structures containing rooms without corners and with strongly lobed outlines. Whether humans would find benefit or pleasure in such rooms will have to be seen.

On the other hand, the self-organization of the ants that produces the nests has much to offer humans in the sense of self-recognition. Studying self-organization in ants can make us aware that much of human activity is also self-organized, that is, that the tasks are accomplished by competent, distributed agents operating under a shared set of rules and interacting directly with the task itself. In humans as in ants, intense communication is not necessary to get the job done, and the outcome is to varying degrees an emergent phenomenon. This is apparent at the scale of economies, but also operates at many scales in human societies. It seems likely that we overestimate the importance of hierarchy and underestimate that of self-organization in human societies. Thus, we might profit from careful analysis of how leaderless groups of individuals with shared behavioral programs, be they ants or humans, interact to get the job done. What subtle cues, changes of venue, current job status, signals and elapsed time cause human or ant workers to change from one task to another, or to stop working? How do these shifts affect the rate and efficiency of work? How does the efficiency and proficiency of workers change with age and experience? And finally, if we view human group tasks as if they were being accomplished by ants, could we gain insight into how humans work?

\section{References}

Beshers, S. N., \& Fewell, J. H. (2001). Models of division of labor in social insects. Annual Review of Entomology, 46, 413-440.

Bonabeua, E., Theraulaz, G., Deneubourg, J.-L., Franks, N. R., Rafersberger, O., Joly, J.-L., \& Blanco, S. (1998). A model for the emergence of pillars, walls and royal chambers in termite nests. Philosophical Transactions of the Royal Society London B, 353, 1561-1576.

Brian, M. V. (1956). Group form and causes of working inefficiency in the ant Myrmica rubra. Physiological Zoology, 29, 173-194.

Buhl, J., Gautrais, J., Deneubourg, J., Kuntz, P., \& Theraulaz, G. (2006). The growth and form of tunnelling networks in ants. Journal of Theoretical Biology, 243, 287-298.

Camazine, S., \& Deneubourg, J.-L. (2003). Self organization in biological systems. Princeton: Princeton University Press.

Cassill, D. L., Tschinkel, W. R., \& Vinson, S. B. (2002). Nest complexity, group size and brood rearing in the fire ant, Solenopsis invicta. Insectes Sociaux, 49, 158-163.

Hart, L. M., \& Tschinkel, W. R. (2012). A seasonal natural history of the ant, Odontomachus brunneus. Insectes Sociaux, 59, 45-54.

Hölldobler, B., \& Wilson, E. O. (2009). The superorganism. New York: W.W. Norton and Co.

Jonkman, J. C. M. (1980a). The external and internal structure and growth of nests of the leaf-cutting ant Atta vollenweideri Forel, 1893 (Hym.: Formicidae). Part I. Zeitschrift fur Angewandte Entomologie, $89,158-173$.

Jonkman, J. C. M. (1980b). The external and internal structure and growth of nests of the leaf-cutting ant Atta vollenweideri Forel, 1893 (Hym.: Formicidae). Part II. Zeitschrift fur Angewandte Entomologie, $89,158-173$.

Karzai, I. N., \& Wenzel, J. (1998). Productivity, individual-level and colony-level flexibility, and organization of work as consequences of colony size. Proceedings of the National Academy of Science, USA, 95, 8665-8669.

Kwapich, C. M., \& Tschinkel, W. R. (2013). Demography, demand, death and the seasonal allocation of labor in the Florida harvester ant (Pogonomyrmex badius). Behavioral Ecology and Sociobiology, 67, 2011-2027. 
Laskis, K. O., \& Tschinkel, W. R. (2009). The seasonal natural history of the ant, Dolichoderus mariae (Hymenoptera: Formicidae) in Northern Florida. Journal of Insect Science. http://jinsectscience. oxfordjournals.org/content/9/1/2.

MacKay, W. P. (1983). Stratification of workers in harvester ant nests (Hymenoptera: Formicidae). Journal of the Kansas Entomological Society, 56, 538-542.

Michener, C. D. (1964). Reproductive efficiency in relation to colony size in hymenopterous societies. Insectes Sociaux, 11, 317-342.

Mikheyev, A. S., \& Tschinkel, W. R. (2004). Nest architecture of the ant Formica pallidefulva: Structure, costs and rules of excavation. Insectes Sociaux, 41, 30-36.

Moreira, A. A., Forti, L. C., Andrade, A. P. P., Boaretto, M. A., \& Lopes, J. (2004a). Nest architecture of Atta laevigata (F. Smith, 1858) (Hymenoptera: Formicidae). Studies on Neotropical Fauna and Environment, 39, 109-116.

Moreira, A. A., Forti, L. C., Boaretto, M. A. C., Andrade, A. P. P., Lopes, J. F. S., \& Ramos, V. M. (2004b). External and internal structure of Atta bisphaerica Forel (Hymenoptera: Formicidae) nests. Journal of Applied Entomology, 128, 204-211.

Penick, C. A., \& Tschinkel, W. R. (2008). Thermoregulatory brood transport in the fire ant, Solenopsis invicta. Insectes Sociaux, 55, 176-182.

Porter, S. D. (1990). Thermoregulation in the fire ant Solenopsis invicta. In Social insects and their environment: Proceedings of the 11th international congress of the IUSSI (p. 660). New York: E. Brill.

Porter, S. D., \& Tschinkel, W. R. (1985). Fire ant polymorphism (Hymenoptera: Formicidae): Factors affecting worker size. Annals of the Entomological Society of America, 78, 381-386.

Rabeling, C., Verhaagh, M., \& Engels, W. (2007). Comparative study of nest architecture and colony structure of the fungus-growing ants, Mycocepurus goeldii and M. smithii. Journal of Insect Science, 7, 40. http://jinsectscience.oxfordjournals.org/content/7/1/40.

Rasse, P., \& Deneubourg, J. L. (2001). Dynamics of nest excavation and nest size regulation of Lasius niger (Hymenoptera: Formicidae). Journal of Insect Behavior, 14, 433-449.

Rink, W. J., Dunbar, J. S., Tschinkel, W. R., Kwapich, C., Repp, A., Stanton, W., \& Thulman, D. K. (2013). Subterranean transport and deposition of quartz by ants in sandy sites relevant to age overestimation in optical luminescence dating. Journal of Archeological Science, 40, 2217-2226.

Sendova Franks, A. B., \& Franks, N. R. (1995). Spatial relationships within nests of the ant Leptothorax unifasciatus (Latr.) and their implications for the division of labour. Animal Behavior, 50, 121-136.

Solomon, S. E., Mueller, U. G., Schultz, T. R., Currie, C. R., Price, S. L., Oliveira da Silva-Pinhati, A. C., Bacci Jr., M., \& Vasconcelos, H. L. (2004). Nesting biology of the fungus growing ants Mycetarotes Emery (Attini, Formicidae). Insectes Sociaux, 51, 333-338.

Tschinkel, W. R. (1987). Seasonal life history and nest architecture of a winter-active ant, Prenolepis imparis. Insectes Sociaux, 34, 143-164.

Tschinkel, W. R. (1993). Sociometry and sociogenesis in colonies of the fire ant, Solenopsis invicta during one annual cycle. Ecological Monographs, 63, 425-457.

Tschinkel, W. R. (1999). Sociometry and sociogenesis of colonies of the harvester ant, Pogonomyrmex badius: Distribution of workers, brood and seeds within the nest in relation to colony size and season. Ecological Entomology, 24, 222-237.

Tschinkel, W. R. (2003). Subterranean ant nest architecture: Trace fossils past and future? Paleogeography, Paleoclimatology and Paleoecology, 192, 321-333.

Tschinkel, W. R. (2004). The nest architecture of the Florida harvester ant, Pogonomyrmex badius. Journal of Insect Science, 4, 21. http://jinsectscience.oxfordjournals.org/content/4/1/21.

Tschinkel, W. R. (2005). The nest architecture of the ant, Camponotus socius. Journal of Insect Science, $5,9$.

Tschinkel, W. R. (2010). Methods for casting subterranean ant nests. Journal of Insect Science, $10,88$. http://jinsectscience.oxfordjournals.org/content/10/1/88.

Tschinkel, W. R. (2011). The nest architecture of three species of Aphaenogaster in north Florida. Journal of Insect Science. http://jinsectscience.oxfordjournals.org/content/11/1/105.

Tschinkel, W. R. (2013). Florida harvester ant nest architecture, nest relocation and soil carbon dioxide gradients. PLOS ONE, 10, 1371.

Wilson, E. O. (1971). The insect societies. Cambridge, MA: Harvard/Belknap. 